and $60 \mathrm{~h}$ respectively. The phase equilibria were studied by $\mathrm{x}-$ ray powder diffraction, metallography, magnetic susceptibility, and electrical resistivity measurements. In addition to three isothermal sections for $\mathrm{Cu}$-rich alloys, [87Kum] determined isothermal contours on the solidus surface. Two isothermal sections for $\mathrm{Cu}$-rich alloys at 1000 and $700{ }^{\circ} \mathrm{C}$ are redrawn from the results of [87Kum] in Fig. 1 and 2.

The solubility of both $\mathrm{Fe}$ and $\mathrm{P}$ increases with increasing temperature. At a given temperature, $\mathrm{Fe}$ reduces the solubility of $\mathrm{P}$; $\mathrm{P}$ in turn reduces the solubility of $\mathrm{Fe}$. The maximum solubility of $\mathrm{Fe}_{2} \mathrm{P}$ in $\mathrm{Cu}$ is $0.55,0.52,0.40,0.26$, and $0.14 \mathrm{~mol} \%$ at $1000,950,900,800$, and $700{ }^{\circ} \mathrm{C}$ respectively [87Kum]. Such data are useful in developing alloy compositions that have a combination of good mechanical strength (derived from a fine distribution of $\mathrm{Fe}_{2} \mathrm{P}$ precipitates) and good electrical conductivity (arising from least solute content in the $\mathrm{Cu}$ matrix phase).

\section{Cited References}

87Kum: A.V. Kumanin, A.K. Nikolaev, and N.I. Revina, "Phase Diagrams and Properties of Copper-Rich Cu-Fe-P Alloys," Izv. Akad. Nauk SSSR, Metally(6), 178-182(1987) in Russian; TR:Russ. Metall. (6) 182-185 (1987). (Experimental;\#)

88Rag: V. Raghavan, "The Cu-Fe-P (Copper-Iron-Phosphorus) System," Phase Diagrams of Ternary Iron Alloys. Part 3, Indian Institute of Metals, Calcutta, 68-73 (1988). (Review;\#)

\# Indicates presence of a phase diagram.

\title{
Fe-In-P (Iron-Indium-Phosphorus)
}

\section{Raghavan}

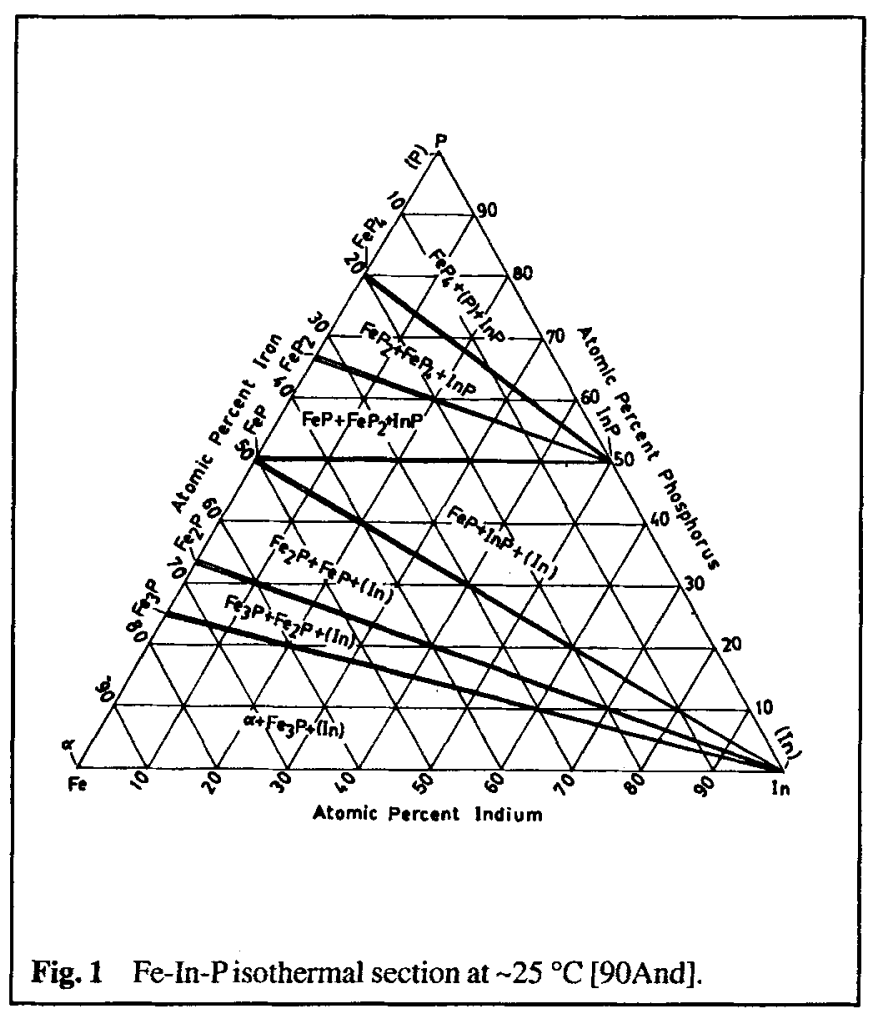

The review by [88Rag] was limited to the solubility data of Fe in InP. [90And] determined an isothermal section for this system at room temperature.

\section{Update}

[90And] used hydrogen-reduced $\mathrm{Fe}$, high-purity In, semiconductor grade InP, and P of $99.9 \%$ purity as starting materials. Thirteen mixtures were heated in evacuated silica tubes at $900^{\circ} \mathrm{C}$ for several weeks. After annealing, the samples were either quenched in water or slowly cooled to room temperature. The phase equilibria on quenched and slowly cooled samples were studied by $x$-ray powder diffraction and DTA techniques. The isothermal section of [90And] at $25^{\circ} \mathrm{C}$ is redrawn in Fig. 1. (In) forms tie lines with the iron phosphides $\mathrm{Fe}_{3} \mathrm{P}, \mathrm{Fe}_{2} \mathrm{P}$, and $\mathrm{FeP}$. InP forms tie lines with $\mathrm{FeP}, \mathrm{FeP}_{2}$, and $\mathrm{FeP}_{4}$. No ternary compounds were found.

Samples quenched from $900{ }^{\circ} \mathrm{C}$ indicated that the isothermal section at $900^{\circ} \mathrm{C}$ is similar to that at room temperature, except that $\mathrm{FeP}_{4}$ is not present at $900^{\circ} \mathrm{C}$. This was confirmed by DTA experiments, which showed two thermal effects during heating due to the melting of In and the decomposition of $\mathrm{FeP}_{4}$.

\section{Cited References}

88Rag: V. Raghavan, "The Fe-In-P System," Phase Diagrams of Ternary Iron Alloys. Part 3, Indian Institute of Metals, Calcutta, 84 (1988). (Review)

90And: M. Andersson-Soderberg, "SolidPhase Equilibriain theFe-In-P System,” J. Less-Common Met., 159, L13-L16 (1990). (Experimental;\#)

\# Indicates presence of a phase diagram. 